\title{
Eleanor Mantel, Janet S. Reddin, Gang Cheng, Abass Alavi (Eds): Nuclear Medicine Technology. Review Questions for the Board Examinations, Fifth Edition. Springer International Publishing AG, 2018. ISBN 978-3-319-62499-0
}

\author{
Luigi Mansi ${ }^{1}$ \\ Published online: 22 June 2019 \\ (C) Springer-Verlag GmbH Germany, part of Springer Nature 2019
}

This 300-page paperback is intended to prepare students and technologists for registry examinations in nuclear medicine technology. As is the case with all publications designed for multiple-choice exam preparation, the structure is based on a test format, providing the most probable questions and a comprehensive explanation of the correct answers. The book is specifically targeted towards applicants to the Nuclear Medicine Technology Certification Board or the American Registry of Radiologic Technologists. But interest in the book may extend to a wider readership, including not only technologists but also medical students and residents worldwide who are interested in nuclear medicine.

The success of the editorial strategy is highlighted by the publication of this fifth edition, which comes 17 years after the first and 5 years after the fourth edition. This edition, therefore, has clearly been updated substantially, eliminating some obsolete concepts and widening the topics of greater current development, in particular positron emission tomography.

The editors are Eleanor Mantel and Janet S. Reddin (University of Pennsylvania, Radiology and Nuclear Medicine, Philadelphia), and Gang Cheng (Philadelphia VA Medical Center, Radiology, Philadelphia), supervised by Abass Alavi, also working at the University of Pennsylvania. Therefore, the authors comprise one technologist and three physicians, one of whom, Abass Alavi, is internationally recognized as one of the most experienced and prestigious masters of nuclear medicine.

Luigi Mansi

mansi.luigi@libero.it

1 Section Health and Development, Interuniversity Research Center for Sustainability (CIRPS), Naples, Italy
After the introduction, the book is structured in 17 chapters, followed by 19 appendices. The first five chapters of the manual present questions on radioactivity, radiopharmacy, and quality assurance; radiation safety; instrumentation and quality assurance; and image presentation and computers. Chapters 6 through 14 then present scintigraphic arguments on the skeletal, central nervous, cardiovascular, and respiratory systems; gastrointestinal tract and genitourinary system; oncology and infection scintigraphy; and finally thyroid, parathyroid, and salivary gland scintigraphy. In Chapter 15, questions on non-imaging procedures and radionuclide therapy are discussed, while the following chapters present arguments concerning patient care (16), positron emission tomography (17), and multimodal imaging (18). A mock examination is presented in Appendix 1, while appendices 2 through 18 discuss answers for each of the chapters. The final appendix provides answers to the mock examination.

Whether for exam preparation or simply refreshing one's basic knowledge of nuclear medicine technology and its practical application, this book could be also suggested as an exercise tool for all those interested in nuclear medicine.

Publisher's note Springer Nature remains neutral with regard to jurisdictional claims in published maps and institutional affiliations. 